COMECHINGONIA. REVISTA DE ARQUEOLOGÍA

Número 15, 2011, pp. 139-154, Córdoba

ISSN 0326-7911

\title{
MATERIALIDAD ARQUEOLÓGICA, PRÁCTICA CIENTÍFICA Y ACTIVACIÓN PATRIMONIAL EN LA CUENCA DEL CHOAPA, IV REGIÓN, CHILE.
}

\author{
Patricia Salatino ${ }^{1}$ y Diego Artigas ${ }^{2}$ \\ ${ }^{1}$ Sección Antropología Social, ICA-FFyL-UBA- CONICET (Argentina). Puán 480 Of. 402 (CABA). \\ patriciasalatino@gmail.com \\ ${ }^{2}$ Universidad Academia de Humanismo Cristiano (Chile). Condell 343 (Santiago).dartigas@academia.cl
}

Presentado el: 14/08/2011 - Aceptado 21/10/2011

\section{Resumen}

En el presente artículo reflexionamos sobre la relación simbólica de los habitantes del Choapa con la materialidad arqueológica, tratando de entenderla en el marco de los procesos históricos que caracterizaron a la provincia. Dicha relación es pensada a partir del diálogo que establecimos con los habitantes de las localidades de Césped y Los Perales en el valle de Illapel, y de Zapallar y San Agustín en el valle de Chalinga; y las ciudades cabeceras de cada valle, Illapel y Salamanca, respectivamente. Analizamos asimismo nuestra intervención en los procesos de activación patrimonial. Concluimos que estos procesos se sostienen sobre discursos patrimoniales construidos a partir de distintos tipos de capital cultural y que sólo en la medida que se incorpore el saber de las comunidades locales se logrará una apropiación espontánea del patrimonio, potenciando así la utilidad social de los restos arqueológicos.

Palabras claves: Arqueología, comunidades, patrimonio, discursos.

\begin{abstract}
In this article we analyze the symbolic relation between Choapa habitants and archaeological materiality, trying to understand it as part of the historical processes that characterized the province. This analysis is based on the dialog we could establish with the inhabitants of Césped and Los Perales in Illapel Valley and from Zapallar and San Agustin in Chalinga Valley; as well as from the principal cities of each valley, Illapel and Salamanca, respectively. We also analyze our intervention in the heritage activation processes. We conclude that these processes are based on heritage discourses constructed upon different kinds of cultural capital and just as long as the local community knowledge get involved, a spontaneous appropriation of heritage can be achieved, increasing the social benefits of archaeological material.
\end{abstract}

Keywords: Archaeology, communities, heritage, discourses. 


\section{Introducción}

La problemática patrimonial se está convirtiendo en un tópico cada vez frecuente en el ámbito arqueológico. Aunque su tratamiento en artículos académicos generalmente se limita a describir tareas de intervención como la puesta en valor, la divulgación científica o la conservación y preservación de sitios arqueológicos; en otras oportunidades se discute el vínculo material y simbólico de las comunidades locales con dichos sitios y el impacto social de la práctica arqueológica en el territorio (Ayala 2007; Chaparro y Soria 2008; Crespo 2006; Criado Boado 2001; Curtoni y Chaparro 2008; Endere y Curtoni 2003; Nielsen 2005; Uribe y Adán 2003; entre otros). Estos planteos ponen a la vista la necesidad de teorizar sobre los procesos de patrimonialización al tiempo que se reflexiona sobre la forma que éstos toman en casos concretos, considerando la triple relación entre comunidades locales, materialidad arqueológica y práctica científica.

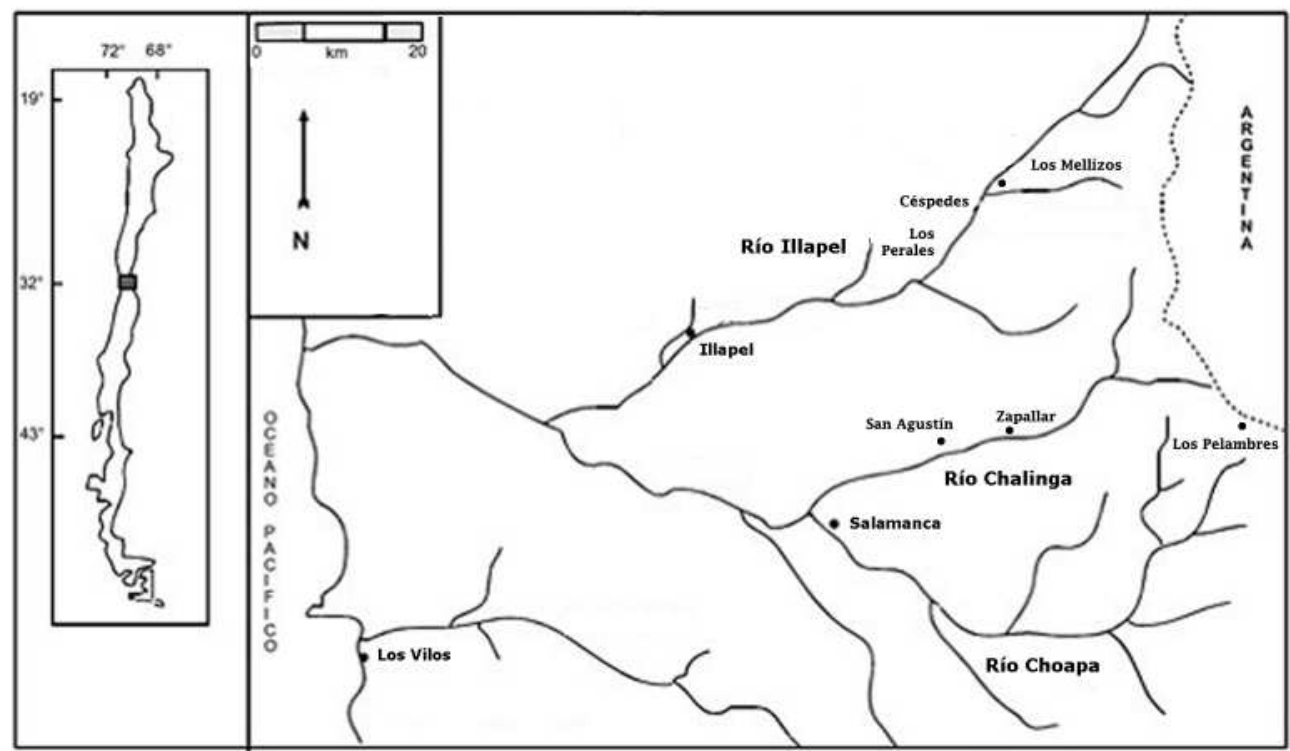

Figura 1. Mapa del valle del Choapa con indicación de las principales localidades mencionadas en el texto.

En este artículo analizaremos la relación de la comunidad local con la materialidad arqueológica y el uso que se le otorga al conocimiento científico en los discursos y prácticas de los distintos actores sociales que intervienen en los procesos de patrimonialización del valle del Choapa, ubicado en la IV Región chilena (Figura 1). Al empezar los trabajos de campo, nuestro objetivo era generar una devolución a la comunidad local y entender su relación con la materialidad arqueológica. Sin embargo, nuestras tareas se diversificaron a la luz de una demanda no prevista, que demostró un interés por apropiarse del conocimiento que nosotros generáramos, tanto por parte de las comunidades como por otros actores sociales pertenecientes a la esfera pública y privada.

En principio, expondremos brevemente lo que entendemos por patrimonio y por procesos de patrimonialización. Luego nos adentramos en la historia de la región a la luz de los relatos que registramos durante las entrevistas realizadas a los habitantes de las distintas localidades del Choapa. En segundo lugar, analizamos la concepción que poseen las comunidades locales de la materialidad arqueológica, tratando de entender su relación 
con la construcción de una memoria colectiva, para finalmente comprender los usos del conocimiento arqueológico en los procesos de activación patrimonial.

\section{Patrimonio, arqueólogos y comunidades}

Podemos pensar en el patrimonio cultural como una de las tradiciones inventadas (Hobsbawn 1990-1991) por la modernidad en los albores de la revolución industrial y el nacimiento de los Estados-nación (Prats 2005). Desde esta perspectiva, el patrimonio cultural vendría "a establecer o simbolizar la cohesión social o la afiliación a grupos o comunidades, reales o ficticias" (Hobsbawn 1990-1991: 103). Sin embargo, en la actualidad existen toda clase de patrimonios, en los que convergen elementos tradicionales y modernos, populares y hegemónicos, originarios y occidentales, construidos y apropiados por diversos grupos sociales, que actúan simultáneamente en el ámbito local y global, trascendiendo las fronteras nacionales. Estos elementos, que forman parte de los procesos de hibridación cultural (García Canclini 1995), convierten al patrimonio en un recurso cultural para actuar en el ámbito político y económico (Yúdice 2003).

En principio, entendemos que el patrimonio cultural se constituye como diferencia siempre a partir de la desigualdad. Es decir que aunque desde una perspectiva antropológica, todos los grupos humanos poseen recursos culturales para asegurar su reproducción social (Bonfil Batalla 2004), no todos son seleccionados, legitimados y activados para convertirse en patrimonio (Prats 2005). Por lo tanto, tienen distinto peso específico dentro del campo patrimonial y para entrar a jugar como capital en otros campos (Bourdieu 1990).

Rescatamos entonces aquella concepción de patrimonio que pone énfasis en la desigualdad, tanto durante el proceso de su construcción social como de su apropiación ulterior. Por estas razones, el patrimonio se presenta como un "recurso para reproducir las diferencias entre los grupos sociales y la hegemonía de quienes logran un acceso preferente a la producción y distribución de los bienes" (García Canclini 1999: 18).

Entonces, para entender los conflictos inherentes al proceso de patrimonialización en un caso particular es necesario entenderlo como un doble proceso: aquel que da cuenta de la valoración y sentido que adquiere un elemento cultural para una comunidad local; y otro mediante el cual ese elemento es seleccionado y activado, en general por actores ajenos a la comunidad (Prats 2005). Esto conlleva que los discursos y prácticas desplegados para activarlo suelen ignorar las concepciones y valoraciones que poseen los elementos culturales seleccionados para las comunidades locales. Como señala Néstor García Canclini, el problema consiste en indagar la coexistencia de la cultura comunitaria con la cultura como distinción (2004: 114).

Entonces, si sólo aquellos elementos que se convierten en patrimonio cultural son los que se activan mediante un discurso autorizado (Candau 2002; Prats 2005; Smith 2006), nos preguntamos ¿qué ocurre con los restos arqueológicos?

Durante la activación, los científicos y expertos hacen una descripción que "deja a la sombra lo esencial: el hecho de que esos rasgos materiales son interpretables" (Sperber 1996 en Candau 2002: 33), es decir, que oscurece su condición de construcción social (Prats 2005). La interpretación científica de la materialidad arqueológica suele centrarse en el sentido histórico del objeto o lugar, vinculado a su uso original (Smith 2005), antes que en los sentidos 
otorgados en el presente (Curtoni y Chaparro 2008), lo que produce una tensión entre una representación del pasado como historia reconstruida vs memoria vivida (Nora 1993).

Sin embargo, actualmente, muchos de los sitios o restos arqueológicos que sustentaron la construcción de identidades nacionales son reclamados como símbolos de una identidad local (p. e. Ayala 2007; Jimenez y Seguel 2003). De esta forma, los grupos que ingresan al campo patrimonial buscan legitimar su patrimonio recurriendo muchas veces a discursos que subvierten la lógica imperante. Pero en otros casos, los expertos son ahora interpelados por las mismas comunidades locales, que buscan apropiarse de un capital cultural socialmente legitimado, como es el saber científico-académico. Esta última es la situación que encontramos en nuestro caso de estudio.

\section{Cuenca superior del río Choapa: los valles de Illapel y Chalinga}

La vida en los valles es fundamentalmente campesina, predominando las actividades agrícolas de baja escala, como las plantaciones frutales, y la cría de ganado caprino, que genera cierta movilidad estacional desde los valles hacia la cordillera en las veranadas. Las familias propietarias conforman sociedades de parceleros y a veces se organizan en cooperativas para comercializar productos específicos como las nueces en las zonas de Céspedes y Los Perales (valle de Illapel; Figura 1). En el valle de Chalinga, el paisaje rural se complementa con pueblos pequeños o villorrios, como los de San Agustín y Zapallar, habitados conjuntamente por familias parceleras y otras que subsisten de fuentes de trabajo no vinculadas con la tierra.

Las localidades rurales mencionadas, junto con las ciudades cabeceras de cada comuna, homónima en el caso del valle de Illapel y Salamanca en el valle de Chalinga, constituyen los lugares donde tuvimos oportunidad de trabajar en el marco del proyecto Fondecyt 1080360 entre los años 2008-2010. Al interior de la cordillera, dentro de la comuna de Salamanca, se encuentra uno de los yacimientos cupríferos más importantes del territorio chileno, que es actualmente explotado por la minera Los Pelambres. Si bien en los valles de Illapel y Chalinga todavía no hay mineras instaladas, ya se han realizado algunas exploraciones. Por otra parte, el uso del cobre en la región se registra desde tiempos prehispánicos (Troncoso 1998).

En la región se han encontrado evidencias de ocupaciones humanas que van desde el Arcaico Temprano (complejo Huentelauquén), pasando por grupos alfareros tempranos (Molle) hasta llegar a los períodos tardíos, representados por los componentes Diaguitachileno e Inka (Troncoso 1998; Jackson, Artigas y Cabello 2002; Pavlovic 2004). Los petroglifos constituyen la evidencia arqueológica más destacada de momentos tardíos. De hecho, el valle del Choapa es una de las regiones con mayor concentración de petroglifos del territorio chileno, superando los 1500 bloques grabados, según lo registrado hasta el momento.

Durante nuestros trabajos de campo, nos propusimos realizar una devolución a las comunidades locales. Con esta intención, nos acercamos a distintas instituciones públicas, como las escuelas rurales de Céspedes, Zapallar y San Agustín; y las municipalidades de Illapel y Salamanca. En este último caso nos derivaron a la Fundación Minera Los Pelambres, que en su momento decidimos no contactar. Sin embargo, en el último año del proyecto, la Fundación nos convocó a nosotros. De esta forma, también pudimos dialogar con actores sociales vinculados al ámbito privado empresarial. 
Mediante estos diálogos quisimos aproximarnos, por un lado, a la visión que tienen los habitantes de los valles tanto de la materialidad como de la práctica arqueológica; y, por otro lado, a los discursos que construyen distintos actores sociales sobre dicha materialidad, atendiendo al uso que hacen del conocimiento científico.

Actualmente, el rol de entidades públicas y privadas en el desarrollo socio-económico de las comunidades del valle es significativo. Sin embargo, existe una diferencia sustancial en la dirección que tienen ciertos programas que fomentan el aprovechamiento de los recursos naturales y culturales del valle para el turismo y aquellas actividades económicas que implican la extracción y, a veces, destrucción de dichos recursos. En este contexto, se inserta la actividad del arqueólogo bajo dos modalidades: el desarrollo de proyectos académicos generalmente financiados con fondos públicos, que pueden ser de gran utilidad para la puesta en valor de sitios arqueológicos; y una arqueología de contrato, que responde al creciente desarrollo de la actividad minera en la zona y el consecuente desarrollo de trabajos de impacto ambiental bajo la legislación vigente (leyes 17.288 sobre los Monumentos Nacionales y 19.300 sobre las Bases Generales del Medio Ambiente).

Por lo tanto, como práctica profesional, la arqueología se ubica en una posición que alterna entre el ámbito público y privado. Con el desarrollo de la actividad minera en la región, se han realizado varios estudios de impacto ambiental, que algunas veces involucraron extensas excavaciones arqueológicas. El caso más conocido corresponde al valle del Mauro (Comuna de Los Vilos), donde junto con el rescate de más de un centenar de sitios arqueológicos, se movilizaron conjuntos enteros de petroglifos de un área donde la minera Los Pelambres realizaría un tranque de relave. Finalmente el tranque se hizo, pero los bloques grabados aún no fueron relocalizados.

Gracias a ésta y otras experiencias, en el marco de obras públicas (por ej. la construcción del embalse El Bato), existe un imaginario social negativo de la práctica arqueológica. Las normativas actuales determinan que los restos extraídos, una vez estudiados, deben permanecer en los museos locales más cercanos. Pero muchas veces, dichos museos no están lo suficientemente cerca de las localidades donde se realizaron las excavaciones (por ej. los museos de Ovalle y La Serena se encuentran a más de $300 \mathrm{~km}$ de las localidades rurales de los valles de Illapel y Chalinga). Por otra parte, en escasas ocasiones, los proyectos de investigación desarrollados en el marco académico realizan algún tipo de devolución a las comunidades, confirmando la idea previamente instalada de que el arqueólogo se lleva cosas valiosas, sin que la gente del lugar sepa más de ellas (Artigas y Salatino 2009; Salatino y Artigas 2010a).

Consideramos que para comprender en profundidad la relación que los habitantes del Choapa establecen con la materialidad arqueológica es necesario comprender cómo se insertan significativamente en sus concepciones del pasado. A continuación resumiremos los principales procesos históricos del valle haciendo referencia a aquellos relatos que pudimos registrar durante los trabajos de campo, para luego adentrarnos específicamente a la valoración de los restos arqueológicos por parte de sus habitantes.

\section{La historia y la memoria}

El paisaje actual del Choapa es producto de la expropiación y repartición de las tierras de los fundos iniciada en 1965 y de la contra-reforma llevada adelante por el régimen militar en 1973, que instala una agricultura de pequeña escala sobre las bases de políticas 
neoliberales, que introducen nuevas formas de diferenciación social entre parceleros vs no-parceleros (Janssen y Livenais 2003). Esta situación se nos manifestó discursivamente en distintas ocasiones:

"Antes acá era un fundo, era un solo dueño. Se expropió este fundo y a la gente que trabaja en el fundo se le cedió una parcela... ahora es una sociedad de parceleros, que tienen derecho a los campos, son todos dueños... pero también hay gente que arrienda."

A partir de 1985, con la instalación de destilerías industriales, la pequeña agricultura se especializó en la producción de uva pisquera y, a partir de la instalación de la compañía cuprífera chilena-japonesa Los Pelambres, la minería volvió a ser una actividad con fuerte presencia en el Choapa (Livenais, Jansenn y Reyes 2003). Actualmente, los habitantes del valle están viviendo el primer traspaso generacional de parcelas, que junto con el auge minero constituyen potenciales factores para nuevas modificaciones del paisaje agrario (Janssen y Livenais 2003). Al respecto, en reiteradas ocasiones se nos manifestó la preocupación por la falta de interés de las nuevas generaciones en conservar y trabajar la tierra, "les importa el dinero, no trabajar la tierra", de manera que migran a otros lugares en busca de nuevas fuentes laborales.

Pero este fenómeno no es novedoso en la región. La historia del Choapa puede ser trazada, por lo menos desde los momentos de la conquista española, en relación con las posibilidades que presentan los recursos naturales disponibles para el desarrollo de distintos emprendimientos socio-económico, sin que esto signifique el mejoramiento de las condiciones de vida de los habitantes del valle.

Durante el proceso de conquista, las poblaciones indígenas del Norte Chico ofrecieron una fuerte resistencia a la penetración hispana, que sólo decayó a partir de 1549, cuando el líder indígena Michimalongo es capturado y exterminado durante las guerras del sur (Vitale 1971). A partir de este momento, los habitantes originarios fueron explotados para la extracción de oro, mineral que le dio fama al valle del Choapa durante el régimen colonial (Camus y Rosenblitt 2000). Con el doble propósito de suplir la merma de mano de obra local (causada por el trabajo forzado y las enfermedades) y reducir los focos de resistencia indígena durante las Guerras de Arauco, a partir de 1580, "huiliches" del sur y "picunches" de la zona central son trasladados hacia las minas del Norte Chico (Vitale 1971).

A finales del siglo XVII se crea el marquesado de Pica, que incluye las haciendas de Illapel y de Pullally, que posteriormente pasan a ser posesión de la familia Irarrázabal, mientras se instaura otra forma minoritaria de tenencia de la tierra constituida por comunidades agrarias, asentadas en suelos marginales de muy baja productividad (Camus y Rosenblitt 2000).

Durante una primera etapa, la economía de las haciendas se orientó a la producción ganadera, en respuesta a la demanda de insumos para la extracción de oro en las minas coloniales (Camus y Rosenblitt 2000). En una segunda etapa, la explotación del cobre reemplaza al oro y la agricultura se vuelve hacia el monocultivo de trigo exportado al Perú, cuando se funda la villa de San Rafael de las Rozas (actual Illapel) con el propósito de evangelizar a los indígenas y cobrar impuestos a los habitantes del valle, dando inicio a la conversión del indio encomendado en obrero asalariado (Camus y Rosenblitt 2000). Este doble proceso de aculturación y mestizaje, dio como resultado la "base demográfica mayoritaria de la emer- 
gente nación chilena" que negó sus orígenes étnicos para asimilarse a la cultura hispana (Waldman 2004: 103).

Finalmente, entre el siglo XVIII y XIX, la actividad agrícola produce un nuevo giro hacia el cultivo de frutas y uvas con una baja productividad. Sin embargo, la actividad minera nunca dejó de ser una fuente alternativa y, por momentos, principal de trabajo, hasta que en el siglo XIX, con el descubrimiento de mejores minerales en el norte y el desarrollo de la industria salitrera, los habitantes del Choapa comienzan a migrar hacia esas regiones; proceso que se vio interrumpido por la crisis mundial de 1929, provocando el retorno de los migrantes a sus lugares de origen (Camus y Rosenblitt 2000). Los fundos de la región recién se desintegraron con la expropiación de los años 1965, iniciada bajo el gobierno de Frei Montalva y profundizada por el gobierno de Allende en los años 70 (Livenais, Jansenn y Reyes 2003). Las referencias a este proceso y los recuerdos de la vida en el fundo son frecuentes en la memoria de los actuales pobladores, tal como lo relata un habitante de San Agustín, dejando en evidencia los abusos a los que estaban sujetos por parte de los propietarios:

"Yo soy nacido aquí en este fundo. Y criado y nacido hasta hoy día. Con 89 años no me he movido nunca. ¿Por qué razón? Lo mal que trabajábamos. Por eso me junté con una mujercita, después apareció un hijito. Andábamos escasos para comer tres personas y ya con el hijito éramos tres. Entonces, pensé yo de salir de aquí a otros lados porque ganaba más. ¿Y con qué salía? (...) me acuerdo bien, cuando salí de aquí, yo hice una salida a Salamanca, por 500 pesos que debía. (...) Llegó el momento de la expropiación aquí. Aquí nos dio una mano Don... ¿Cómo se llama el candidato que hubo este año? ¡Frei! El padre de Frei, cuando llegó él a ser presidente, entonces aparecieron las leyes aquí. Con decirte que no se permitían las revistas aquí, no se permitía que la gente se educara... ¿Para qué era eso? Para que cuando hubieran elecciones, no tener derecho a voto (...) entonces ahí llegábamos, sacaban el voto ellos y marcaban la preferencia, ellos. Este votito es el que vale. Te lo daban que lo eches en el bolsillo, que no te lo vea nadie. ' $Y$ ahí te van a hacer firmar un libro. Lo firmai tú, te van a dar un voto, un papel así de este mismo tamaño. $Y$ así, cuando vai a dar la preferencia, te lo guardas en el bolsillo bien seguro. Y este de aquí lo echai al sobre y sali y lo vai a depositar en la urna.' Y esa lección la daban los patrones en las elecciones. Por eso es que no querían que la gente aprendiera a leer, porque eran muchos los que se entusiasman a comprar un diario, una revista y se aprendian las leyes. Después salió la radio y no permitían que nos compremos un radio. Y cuando salió Frei entonces salieron las leyes aquí. Frei Montalva. Y después de él vino este señor... ¿cómo se llamaba, que lo mataron...? Allende. Entonces él entregó las tierras aquí. Y vino a dividir aquí las tierras en parcelas y sitios."

Así como los propietarios manipulaban impunemente a los habitantes del fundo, también se otorgaban el derecho a tomar del valle lo que quisieran, así como lo sugiere la referencia frecuente a eventos de extracción de petroglifos en tiempos pasados. "Sacaban hartos pedazos y se lo llevaban." En algunos casos se nos mencionó que los responsables eran miembros de la familia propietaria, pero en otros se trata simplemente de un recuerdo impreciso, pero igualmente presente. "Tiempo atrás se llevaron harto. Llegaban, los sacaban con cincel, se los llevaban." Es posible que estos eventos, junto con el posterior inicio de los trabajos arqueológicos, que especialmente en casos de impacto ambiental recibieron una valoración negativa por parte de las comunidades, provocaran una particular sensibilización por el resguardo de los petroglifos. Pero también creemos que la valoración otorgada a la materialidad arqueológica 
es producto de la vida cotidiana en el campo y de un paisaje social del cual los restos del pasado forman parte.

Las cosas de los indios y el paisaje campesino

Tanto petroglifos como restos más pequeños y móviles descansan en los campos, donde las personas trabajan el sembrado, o en las laderas de los cerros, por donde circulan acarreando a sus animales. La relación de las comunidades de los valles de Illapel y Chalinga con los restos arqueológicos es una de tipo cotidiano, aunque el encuentro con estas piezas del pasado se considera con suerte. No así en el caso de los restos humanos, que según se nos ha informado a veces son vueltos a enterrar en otro lugar donde no sean perturbados.

De hecho, la familia Mánquez cuenta que todavía escuchan los sollozos de la persona cuyos restos fueron encontrados por uno de ellos y luego rescatados por un equipo de arqueólogos para su estudio. Los arqueólogos encargados del rescate entregaron los informes de los estudios realizados a la familia, pero no así el esqueleto (bautizado como "Paulina Arenas", pese a que los análisis lo asignaron al sexo masculino), que permanecen en el depósito del Museo de Historia Natural de Valparaíso (Pavlovic 2007). La devolución de dichos restos para tranquilidad de la familia es un pedido que aún queda pendiente, pero difícil de concretar por las condiciones bajo las cuales debería asegurarse su conservación. Este relato demuestra la sensibilidad de los habitantes del lugar para aquellos que vivieron antes que ellos en un pasado remoto. Pero este respeto no sólo se evidencia en el trato otorgado a los restos óseos, sino también por la valoración dada a los utensilios y objetos de "los indios".

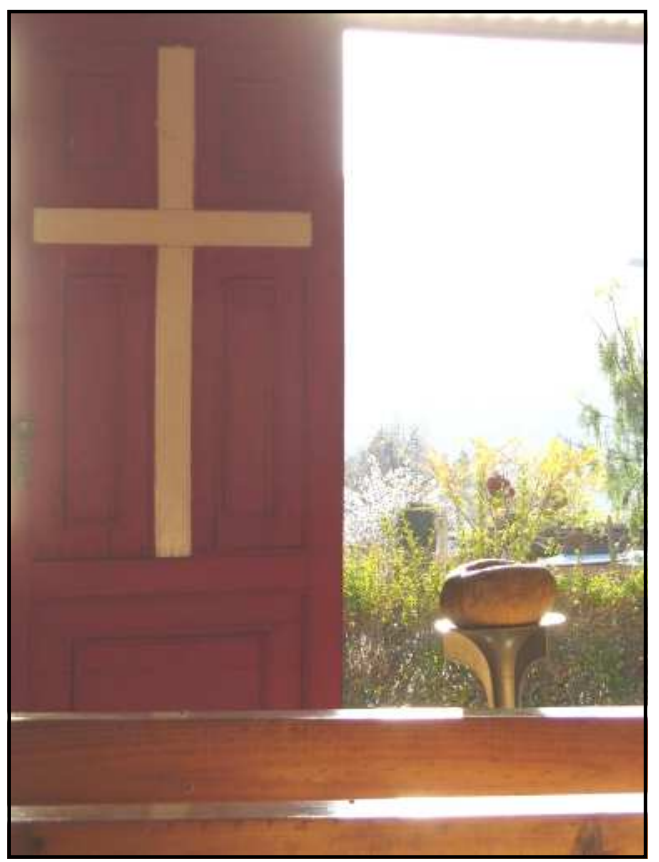

Figura 2. Mortero de piedra en la Iglesia de San Agustín.
Muchos habitantes poseen colecciones de piezas arqueológicas bien cuidadas y cuando se les pregunta por ellas, se perciben dos cosas: 1) la idea de que es una práctica aprehendida desde la infancia, que sus padres ya juntaban las "cosas de los indios", a tal punto que algunas piezas poseen mayor valor afectivo por ser una herencia familiar; y 2) que las cosas conservadas demuestran la habilidad y destreza que tenían los antiguos habitantes para vivir en el valle. Es destacable que en escasas excepciones (Salatino y Artigas 2010a) se menciona su valor económico.

Un hecho que nos da la pauta de que los objetos arqueológicos actualizan nuevos sentidos en el presente se encuentra en la Iglesia de San Agustín (Figura 2), donde un mortero prehispánico ubicado a la entrada es empleado como pila de agua bendita. Este contexto de re-significación espontáneo, establece un nexo simbólico entre dos mundos antiguamente en tensión -la religión católica y los pueblos ori- 
ginarios-, que actualmente constituyen parte del paisaje social del valle. Paradójicamente, en distintos lugares, existen petroglifos que dan cuenta de dicha tensión, a través de representaciones de cruces, escenas de monta y nombres, que conviven junto a motivos de momentos previos en las rocas.

Se puede establecer, de hecho, que la relación con los petroglifos es de una naturaleza distinta a la que se establece con los restos móviles. Los petroglifos forman parte en un espacio habitado, recorrido y recreado comunitariamente, convirtiéndose así en un referente para la memoria colectiva. Los bloques con grabados se ubican en las laderas de los cerros, en las márgenes de los ríos, en los pasos cordilleranos, que son los espacios comunes empleados cotidianamente por los habitantes del valle. Los petroglifos se presentan así como parte de un paisaje social del que todos participan.

Este paisaje está cargado de sentidos que no sólo remiten a recuerdos del pasado y usos del presente, sino también a un rico folklore vinculado al mundo de los brujos y otros seres mitológicos. La materialidad relacionada a este mundo se relaciona con lugares del paisaje, como la conocida Raja de Manquehua, identificada como un lugar de encuentros de brujos, tal como se describe en el siguiente relato:

"Entonces aquí, aquel cerro lo llaman Manquehue, ¿no? Según los cuentos, que hay un encanto ahí. Entonces, un caballero de este lado ahí campeando unos animalitos, se encuentra con una señorita. ¿Qué anda haciendo por aquí usted caballero? Ando campeando unos animalitos. ¿Y usted? También vine por aquí a dar una vuelta. Conversando, conversando, no supo: estaba encantado... en Manquehue, dentro de un palacio, como 20 días. Ahí habían distinta gente, se servían los mejores manjares, bailaban. Tuvo una diversión, todo bueno. Visto tanto cariño y era joven, salieron a bailar y se enamoraron. Entonces él, como se enamoró, tomaba, tomaba y se cura. Entonces la niña le dijo: lo voy a echar a dormir para que le pare la cura. Al otro día en el campo, recuerda, donde mismo encontró la niña, ahí mismo durmiendo estaba abrazado con un esqueleto de caballo. Ese es la historia del encanto, de los brujos."

Recientemente, agrupaciones locales han buscado proteger este lugar ante eventuales acciones destructivas de las mineras instaladas en la zona, pidiendo que lo declaren Monumento Arqueológico y Santuario de la Naturaleza, lo que pone en evidencia los escasos instrumentos legales que existen actualmente en Chile para la protección del patrimonio inmaterial.

Por el contrario, el encuentro de piezas arqueológicas móviles conlleva la apropiación individual y posibilita su traspaso como parte de una herencia familiar. Es decir, que los petroglifos participan mayormente del espacio social comunitario, mientras que las piezas del espacio social doméstico. Pero creemos que ambos se configuran como referentes de la memoria colectiva, en la medida que refieren objetivamente a un pasado, que habilita la recreación de sentidos en el presente en consonancia con procesos de construcción identitaria, lo que por supuesto da lugar también al olvido. A pesar de la abundante toponimia y apellidos originarios de lenguas americanas ${ }^{1}$ y la trasmisión de un folklore que probablemente tenga el mismo origen (Ponce 1997), los habitantes del valle sienten una ruptura histórica con los "indios", que "desaparecieron con las guerras de la conquista"; lo que demuestra la efectividad con que fueron hispanizados y occidentalizados los habitantes de estas regiones. 
Sin embargo, percibimos una identificación con los antiguos pobladores, que se da a través del habitar y vivir un paisaje, que presenta la misma morfología y ofrece los mismos recursos naturales que en el pasado más remoto. Cuando preguntamos directamente sobre los modos de vida del pasado, nos dijeron que "ellos eran muy habidosos", que sabían cómo aprovechar los recursos con inteligencia. La interpretación que hacen niños y adultos de los motivos rupestres da cuenta de esta profunda identificación vivida a través del paisaje habitado. Frecuentemente, se "leen" motivos que nosotros clasificamos en "abstractos" y "figurativos", en relación con referentes conocidos, como círculos yuxtapuestos que representan huevos de rana y zoomorfos que, dependiendo de algunos detalles formales, pueden significar perros o guanacos. En todos los casos, las formas se interpretan en función del mundo conocido y cotidiano, lo visible y lo vivido, que convive con el mundo mítico de los brujos, aquelarres y seres nocturnos, lo invisible y lo contado. Pero ambos mundos configuran un mismo paisaje, cuya integridad material y simbólica es amenazada por la acción de actores externos a la comunidad, como suelen manifestar con respecto a las mineras y los arqueólogos. Si las mineras son una amenaza para los recursos naturales, el arqueólogo lo es para los recursos culturales.

\section{Activación patrimonial y usos del conocimiento arqueológico}

Desde hace algunos años, los petroglifos empezaron a adquirir un nuevo valor en el marco de programas que fomentan el turismo rural, pero la materialidad arqueológica también ha sido parte de un proceso más amplio de activación patrimonial. Según nuestra experiencia, pensamos que cada actor social tiene sus intereses particulares y que muchas veces las activaciones tienen por objetivo legitimar la posición de poder que ocupa la institución que las promueve. En este contexto, el conocimiento científico se convierte en una valiosa herramienta para construir los discursos patrimoniales (Prats 2005) siendo manipulado para la concreción de dicho objetivo.

Los procesos de activación en el valle del Choapa se ven como consecuencia de la acción dirigida de dos clases de actores sociales. Por un lado, la acción del poder político, a través de organismos públicos o privados de financiamiento para el desarrollo de proyectos productivos, educativos o turísticos. Generalmente, se convocan técnicos y profesionales de distintas disciplinas, para realizar intervenciones puntuales, pero sin hacer un análisis previo de la realidad socio-cultural local. Esta situación conlleva muchas veces a que el programa se trunque, una vez finalizado el seguimiento técnico y la adjudicación de fondos, cosa que carece de importancia para el organismo financiador, ya que el principal objetivo es generar una buena imagen de la gestión gubernamental de turno. Cuando llegamos al valle de Illapel distintas agrupaciones locales estaban recibiendo fondos para diseñar un sendero turístico que involucraba la apertura de dos sitios arqueológicos ${ }^{2}$ : Los Mellizos (Césped) y Loma Las Burras (Sendero del Diaguita en Los Perales).

Por otra parte, actúan actores vinculados al campo económico, que dependiendo de los intereses puestos en el territorio pueden resultar todavía menos efectivos para una adecuada "puesta en valor" y apropiación del patrimonio en cuestión. Este tipo de intervención la observamos principalmente el valle de Chalinga ${ }^{3}$ y en Salamanca. La fuerte presencia de la empresa minera Los Pelambres en esta ciudad, se evidencia por la inversión realizada en infraestructura y proyectos de diversa índole, muchos de los cuales en conjunto con la Municipalidad. 
Ambos tipos de actores demandan el apoyo del saber científico para el desarrollo de proyectos patrimoniales, sin embargo cada uno obtiene beneficios particulares en cada caso. Las mineras disponen directamente de este saber a través de los informes que resultan de los trabajos de impacto ambiental, a los que sacan provecho como se manifiesta en la siguiente frase extraída de la página web de la minera Los Pelambres:

"El valioso patrimonio arqueológico del Valle del Choapa permaneció escondido en gran medida hasta los trabajos de construcción de Minera Los Pelambres, permitiendo que fuera rescatado, investigado y conservado bajo condiciones que permiten asegurar la transmisión de su legado cultural." (Fuente: http://www.pelambres.cl/m_ambiente/das_1.html)

Es fácil percatarse del confuso y engañoso discurso en esta afirmación. En principio, los "trabajos de construcción" son, antes que nada, trabajos de destrucción, que afectan directamente la integridad de diversos recursos naturales y culturales del valle, incluyendo los arqueológicos. Siguiendo la lógica que las mismas mineras promueven en sus charlas de inducción: "sin accidentes no hay necesidad de salvatajes"; considerando además que, bajo la legislación actual, sólo un porcentaje del recurso impactado será "investigado y conservado", mientras que el resto será totalmente destruido. Por último, lo que consideramos el punto más importante, el hecho de que se lleven adelante estas acciones no asegura bajo ningún punto de vista "la trasmisión de su legado cultural", que más bien depende de un adecuado programa de educación formal o informal.

En la medida que este saber no se ponga a disposición de las personas, la imagen pública que las mineras buscan construir nunca será creíble. Por esta razón, pensamos que la Fundación creada por la minera realizó las jornadas de fomento a la cultura, a las que fuimos invitados, entre otros especialistas.

Específicamente, se nos contactó para invitarnos a participar de un seminario sobre "Patrimonio, Identidad y Cultura" organizado conjuntamente con la Minera Vale y la Ilustre Municipalidad de Salamanca. A la conferencia asistieron profesores, alumnos de colegios municipales y miembros de la comunidad. Creemos por tanto que la convocatoria es parte de una estrategia para revertir la imagen pública negativa que la empresa posee actualmente y asimismo justificar los trabajos arqueológicos realizados durante las evaluaciones de impacto ambiental.

En Illapel, tuvimos la oportunidad de trabajar con la directora de la Casa de la Cultura, la Sra. Zaida Dabed, para montar una exposición arqueológica, con motivo de la celebración del bicentenario de la ciudad. La exposición se tituló "Arqueología en Illapel: descubriendo a los antiguos habitantes del Choapa" y se armó con piezas donadas a la municipalidad, que estaban guardadas en un depósito desde hacía varias décadas. Asimismo, diseñamos una serie de pendones (plotters) con texto e imágenes, que podrían ser trasladados y montados en otros espacios. La exposición fue promocionada por los medios locales, inaugurada por el alcalde de la ciudad y concurrida por cientos de visitantes. Creemos que la atención recibida se debe tanto al valor otorgado a las piezas, muchas de las cuales fueron donaciones de colecciones privadas, como al interés por conocer los resultados de las investigaciones arqueológicas de los últimos años. La existencia de esas piezas era de público conocimiento y se corría el rumor de que habían sido robadas o perdidas en el transcurso de los múltiples traslados a las que fueron sometidas. Al colaborar en la municipalidad y la Casa de la Cultura, ofrecimos 
un medio para poner a disposición del pueblo illapelino un capital cultural desigualmente distribuido hasta el momento (García Canclini 1999).

Todas las acciones que tienden a visibilizar o "activar" el patrimonio cultural de la región, lo que hacen es poner el foco en determinados elementos que revisten algún valor para los actores que las promueven. De esta forma, se ponen en circulación discursos y concepciones sobre el patrimonio, que poco incorporan de la valoración y concepción previamente existente en las personas que conviven con dichos elementos. Se reproduce así en el discurso y en la práctica un atomismo, donde lo natural se escinde de lo cultural, lo material de lo inmaterial.

Antes decíamos que las comunidades locales valoran a los restos arqueológicos por la identificación con los antiguos habitantes del valle, que resulta de compartir un paisaje y un modo de vida rural. Aunque no existe una celebración manifiesta de dicha identidad, creemos que los procesos de activación cultural promovidos "desde arriba" generaron una consciencia del valor que ciertos elementos que la conforman reviste para actores externos a la comunidad (mineras, arqueólogos o turistas).

Las distintas agrupaciones locales que buscaban convertir los sitios de arte rupestre en un recurso turístico, manifestaron inmediatamente su interés por obtener nuestra colaboración. No necesariamente reconocían el valor agregado que le otorga el conocimiento científico al producto turístico, sino que la mayor preocupación giraba en torno a "tener algo para decir". Lo paradógico es que ellos tenían tanto para decir sobre los restos arqueológicos como nosotros. En este punto iniciamos un diálogo en pos de construir un discurso conjunto sobre los petroglifos e incorporar el conocimiento local (Artigas y Salatino 2009).

\section{Conclusiones}

Al ocupar un espacio intermedio entre las instituciones y las personas, pudimos observar los distintos tipos de saberes que circulan en nuestras sociedades. Para los actores ajenos a la comunidad, que actúan en el territorio (empresas mineras, funcionarios públicos y arqueólogos), el patrimonio del valle se restringe a aquello que posee valor desde un punto de vista económico, legal o científico. Pero como vimos con el caso de la Raja de Manquehua (en Chalinga) o del entierro de "Paulina Arenas" (en Illapel), estos valores pueden entran en tensión con aquellos que forma comparte la comunidad local, donde "lo ideológico se torna vivencial" (Prats 2005: 26)

Por otro lado, por los procesos históricos particulares que se desarrollaron en la región (aunque similares a otras regiones latinoamericanas), la memoria colectiva fue forzada a olvidar. En este sentido, los arqueólogos tenemos un compromiso con las historias no contadas. Pero la única forma de establecer un vínculo con el presente es trascender la "ruptura metafísica" entre arqueología e historia (Haber 1999), que también se reproduce en las investigaciones científicas del valle del Choapa.

Por otra parte, es necesario comprender la relación simbólica que las personas tienen actualmente con la materialidad que estudiamos, incorporando la mirada antropológica a la práctica arqueológica ${ }^{4}$, ya que es la única forma de hacer una adecuada devolución a la comunidad. 
Por último, tener claro qué actores están promoviendo las activaciones culturales, de manera de tener claro a qué intereses estamos favoreciendo con nuestra intervención. En nuestro caso, la reflexión sobre el rol que cumplimos los arqueólogos en los procesos patrimoniales nos llevó a considerar las siguientes premisas a futuro:

1) Poner a disposición de las comunidades el conocimiento producido por nosotros, para que no sea un capital exclusivo de otros agentes de poder -empresas o Estado-.

2) Partir de un diálogo con las comunidades, para que la entrega de este saber sea sensible a los conocimientos y valoraciones previas sobre lo arqueológico, evitando caer en una imposición.

3) Incorporar ambos tipos de saberes, el científico y el comunitario, a los discursos patrimoniales de manera que favorezca el proceso de identificación con (y apropiación de) el producto patrimonial. Esto sólo se logra profundizando el diálogo, permitiendo al arqueólogo recuperar los sentidos ocultos de su objeto de estudio en el presente.

\section{Agradecimientos}

No podemos terminar este texto sin agradecer a las personas que apoyaron incondicionalmente nuestro trabajo en terreno: la Señora Zaida Dabed, encargada de la Casa de la Cultura de Illapel en el año 2009; el antropólogo Jimmy Núñez, que actualmente trabaja en la Casa de la Cultura de Illapel, y que continúa con el trabajo de difusión del patrimonio arqueológico en las escuelas rurales. La Familia Mánquez de Los Perales, las profesoras Romina (escuela Los Perales) y María (escuela de Zapallar), que nos apoyaron en nuestro trabajo con los niños. Y a todas las familias de los valles de Illapel y Chalinga que nos abrieron sus puertas y aceptaron amablemente contarnos sus historias.

\section{Notas}

${ }^{1}$ Toponimia como Chalinga, Illapel, Manquehua de posible raíz mapuche (Carvajal 1998); y apellidos como Manque o Mánquez, en su forma hispanizada.

${ }^{2}$ Algunos de los programas y fondos que nosotros observamos en marcha o recientemente ejecutados en el valle de Illapel fueron: "Choapa Emprende" del Ministerio del Interior y Seguridad Pública de la Gobernación de la Provincia del Choapa; fondos otorgados por la Corporación Nacional Forestal de Chile para cartelería sobre flora en el sitio arqueológico "Los Mellizos"; Proyecto "Los Perales, comprometido con la conservación y difusión de nuestro patrimonio cultural" financiado por la Comisión Nacional del Medio Ambiente; Programa "Formación y Capacitación para Mujeres del sector Rural" del convenio entre el Instituto Nacional de Desarrollo Agropecuario y la Fundación para la Promoción y Desarrollo de la Mujer (INDAP-PRODEMU).

${ }^{3}$ En el valle de Chalinga solamente conocimos un "Proyecto Conjunto de Apoyo a la Educación Patrimonial", ejecutado por la Municipalidad de Salamanca, la Escuela de San Agustín y la Gerencia Corporativa de Exploraciones de CODELCO (empresa minera estatal).

${ }^{4}$ Tanto en la Universidad de Chile como en la Universidad de Buenos Aires, los planes para la especialización en Arqueología parten de una formación previa antropológica.

\section{Bibliografía citada}

Artigas, D. y P. Salatino

2009 Piedras, Miradas y Discursos El arte rupestre a los ojos de las localidades de Césped y Los Perales Illapel, Chile. Actas del Congreso Internacional de Arte Rupestre, pp. 1057-1071. IFRAO. 
Ayala R., P.

2007 Relaciones entre atacameños, arqueólogos y Estado en Atacama (norte de Chile). Estudiosatacameños 33: 133-157.

Bonfil Batalla, G.

2004 Pensar nuestra cultura. DGCPI Diálogos en acción, primera etapa: 117-134.

Bourdieu, $\mathrm{P}$.

1990 Algunas propiedades de los campos. Sociología y cultura, pp. 135-141. México, Conaculta.

Camus y Rosenblitt

2000 Desarrollo y medio ambiente en la cuenca del Choapa. Un enfoque histórico. Scripta Nova. Revista Electrónica de Geografía y Ciencias Sociales 56.

Candau, J.

2002 Memoria e Identidad. Traducido por E. Rinesi. Ediciones del Sol, Buenos Aires.

Carvajal Lazo, $\mathrm{H}$.

1998 Ovalle y la toponimia indígena del Limarí. Caburga, La Serena.

Criado Boado, F.

2001 Problems, functions and conditions of archaeological knowledge. Journal of Social Archaeology 1(1):126-146.

Chaparro, M. G. y S. S. Soria

2008 Comunidades anfitrionas, turistas y arqueólogos: un equilibrio difícil de lograr. Los Monumentos Nacionales en la Provincia de Salta, Argentina. Comechingonia Virtual 2(1): 1-23.

Curtoni, R. y M. G. Chaparro

2008 El espejo de la naturaleza y la enfermedad histórica en la construcción del conocimiento. Intersecciones en Antropología 9: 213-227.

Crespo, C.

2006 "Entre el "deber" y el "derecho": patrimonio arqueológico y obligaciones sociales en Patagonia Argentina. Intersecciones en Antropología 7: 63-75.

Endere, M. and R. Curtoni

2003 Patrimonio, arqueología y participación: Acerca de la noción de paisaje arqueológico. Análisis, interpretación y gestión en la Arqueología de Sudamérica. Universidad Nacional del Centro, Buenos Aires.

García Canclini, N.

1995 Hybrid cultures: strategies for entering and leaving modernity. University of Minnesota Press, Minneapolis.

1999 Los usos sociales del patrimonio cultural. Patrimonio etnológico. Nuevas perspectivas de estudio: $16-33$.

2004 Diferentes, desiguales o desconectados. CIDOB d'afersinternacionals 66: 113-132. 
Haber, A.

1999 Caspinchango, la ruptura metafísica y la cuestión colonial en la arqueología sudamericana: el caso del noroeste argentino. Rev. do Museu de Arqueologia e Etnologia 3: 129-141.

Hobsbawm, E.

1990-1991 La invención de las tradiciones. Traducido por T. Ranger. Revista Uruguaya de Ciencia Política 1990-1991: 97-107.

Jackson, D., D. Artigas y G. Cabello

2002 Trazos del Choapa. Universidad de Chile, Santiago.

Janssen, E. y P. Livenais

2003 Solidaridad familiar y sistema de pequeña agricultura en el Alto Valle del Choapa. Universidad de Chile-Institut de recherche pour le développement, pp. 417-437. IRD-Universidad de la Serena.

Jiménez, C. y R. Seguel

2003 De lo técnico profesional a lo social: un proceso transhumántico. Chungará 35(2): 315320.

Livenais, P., E. Jansenn y H. Reyes

2003 Las transformaciones territoriales contemporáneas de la pequeña agricultura del alto valle del Choapa. Universidad de Chile-Institut de recherche pour le développement, pp. 361-396. IRDUniversidad de la Serena

Nielsen, A.

2005 Quien valora el patrimonio. Ambiente natural y Desarrollo: Propuesta para la Conservación de la Biodiversidad y el Paisaje. FUNDANDES, San Salvador de Jujuy.

Nora, P.

1993 Entre memória e história: a problemática dos lugars. Projeto história 10: 7-28.

Pavlovic, D.

2004 Dejando Atrás la Tierra de Nadie: Asentamientos, contextos y movilidad de las comunidades alfareras tempranas del Choapa. Werken 5: 39-46.

2007 Salvataje Contexto Funerario Sitio Arqueológico Parcela Alejandro Manque, Sector F, sector de Césped, Comuna de Illapel, provincia de Choapa, IV Región de Coquimbo. Informe Preliminar. Consejo de Monumentos Nacionales. Santiago de Chile. MS.

Ponce, B.

1997 El Regreso del Arriero, Mitos y Leyendas de la Región de Coquimbo. Centro Cultural Changos, Coquimbo.

Prats, L.

2003 Patrimonio + turismo $=$ ¿desarrollo? PASOS. Revista de Turismo y Patrimonio Cultural 1(2): 127-136.

2005 Concepto y gestión del patrimonio local. Cuadernos de Antropología Social 21:17-35. 
Salatino, P. y Artigas D.

2010 El patrimonio como capital cultural objetivado: aproximación inicial a dos casos de estudio en la provincia del Choapa, IV Región, Chile. Arqueología Argentina en el Bicentenario de la Revolución de Mayo. Actas del XVII Congreso Nacional de Arqueología Argentina, tomo V, pp. 539-544. Mendoza.

Smith, L.

2006 Uses of heritage. Routledge, London.

Troncoso, Andrés

1998. La cultura Diaguita en el valle de Illapel: una perspectiva exploratoria. Chungará 30(2): 125-142.

Troncoso, A.

1998. La cultura Diaguita en el valle de Illapel: una perspectiva exploratoria. Chungara 30(2): 125-142.

Uribe Rodríguez, M. and L. Adán Alfaro

2003 Arqueología, patrimonio cultural y poblaciones originarias: reflexiones desde el desierto de Atacama. Chungará_35(2): 295-304.

Vitale, L.

1971 Interpretación marxista de la historia de Chile. La Independencia política, la rebelión de las provincias y los decenios de la burguesía comercial y terrateniente. Prensa Latinoamericana.

Yúdice, G.

2002 El recurso de la cultura. Usos de la cultura en la era global. GEDISA. Barcelona.

Waldman M., G.

2004 Chile: indígenas y mestizos negados. Política y Cultura: 97-110. 